Florida International University FIU Digital Commons

FIU Electronic Theses and Dissertations

University Graduate School

7-7-2016

\title{
Vocal Flexibility and Regional Variation in Free- Tailed Bat Song
}

Israel Salazar

isala004@fiu.edu

DOI: $10.25148 /$ etd.FIDC000722

Follow this and additional works at: https://digitalcommons.fiu.edu/etd

Part of the Behavior and Ethology Commons, and the Biology Commons

\section{Recommended Citation}

Salazar, Israel, "Vocal Flexibility and Regional Variation in Free-Tailed Bat Song" (2016). FIU Electronic Theses and Dissertations. 2602. https://digitalcommons.fiu.edu/etd/2602

This work is brought to you for free and open access by the University Graduate School at FIU Digital Commons. It has been accepted for inclusion in FIU Electronic Theses and Dissertations by an authorized administrator of FIU Digital Commons. For more information, please contact dcc@fiu.edu. 


\section{FLORIDA INTERNATIONAL UNIVERSITY}

Miami, Florida

VOCAL FLEXIBILITY AND REGIONAL VARIATION IN FREE-TAILED BAT SONG

A thesis submitted in partial fulfillment of

the requirements for the degree of

MASTER OF SCIENCE

in

BIOLOGY

by

Israel Salazar 
To: Dean Michael R. Heithaus

College of Arts, Sciences and Education

This thesis, written by Israel Salazar, and entitled Vocal Flexibility and Regional Variation in Free-tailed Bat Song, having been approved in respect to style and intellectual content. Is referred to you for judgment.

We have read this thesis and recommend that it be approved.

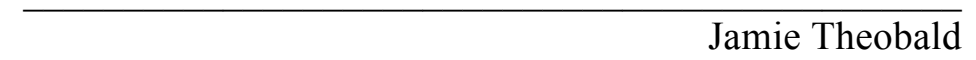

Kirsten Bohn Co-Major Professor

Philip Stoddard Co-Major Professor

Date of Defense : July 7, 2016

The thesis of Israel Salazar is approved

Dean Michael R. Heithaus College of Arts, Sciences and Education

Andrés G. Gil Vice President for Research and Economic Development And Dean of the University Graduate School

Florida International University, 2016 


\section{DEDICATION}

I dedicate this thesis to my family, whose immense sacrifice and perpetual dedication has made into everything I am today. This work would not have been possible without their love, support, and encouragement. 


\section{ACKNOWLEDGMENTS}

I wish to thank my major professors Dr. Kirsten Bohn and Dr. Philip Stoddard for their guidance, support and encouragement. I am extremely thankful for all that they have taught me about science and about life. Kisi's contagious passion for bats, and Phil's love of animal behavior and communication, combined perfectly into a mentorship team that left nothing to be desired. Thanks again for going above and beyond the call of duty to help. I would also like to thank Dr. Jamie Theobald for his support, and valuable input and ideas. I would further like to thank the wonderful people who hosted me and or gave me access to their property to allow me to conduct my fieldwork; Frank Ridgley from the Miami Zoo, Frank \&Teresa from Pebble Hill Grove, and especially to Laura and Thom Finn from Fly by Night Inc. Last but certainly not least, I would like to thank; Giselle, Marcella, Maria, and Ines for their invaluable help with data collection and processing, as well as all the members of the Bohn, and Stoddard labs for all of their helpful comments and suggestions. 


\begin{abstract}
OF THE THESIS
VOCAL FLEXIBILITY AND REGIONAL VARIATION IN FREE-TAILED BAT SONG by
\end{abstract}

Israel Salazar

Florida International University, 2016

Miami, Florida

Professor Kirsten Bohn, Co-Major Professor

Professor Philip Stoddard, Co-Major Professor

While much work has been done on regional vocal variation in birds, relatively few studies have found evidence of similar variation in mammalian vocalizations. This study quantifies individual, colonial, and regional level variation in T. brasiliensis songs in the southeastern United States. Brazilian free-tailed bats (Tadarida brasiliensis) are among a handful of mammals that produce complex, hierarchically structured vocalizations. Their songs are composed of multiple syllables that are combined into three phrases that vary in number and order across renditions. Tadarida brasiliensis songs showed considerable amount of variation, and differed significantly between locations in terms of syllable structure and song syntax. Some of the variation observed was not correlated to geographical distance, and is unlikely to be explained by genetic divergence or differences in habitat use. These results indicate the existence of vocal dialects and a possible role of vocal production learning in dialect formation in this species. 
TABLE OF CONTENTS

CHAPTER

PAGE

Introduction 1

Methods $\quad 5$

- Variation in Syllable Acoustics 6

- Spectro-temporal Variation 7

- Variation in Song Syntax 8

- Variation and Distance 9

- Variation and Migration 9

Results $\quad 10$

- Variation in Syllable Acoustics 10

- Spectro-temporal Variation 11

- Variation in Song Syntax 11

- Variation and Distance 12

- Variation and Migration 12

Discussion 13

References 23

Tables and figures $\quad 31$ 


\section{LIST OF FIGURES}

FIGURE

PAGE

1. Brazilian free-tailed bat songs 33

2. Map of study sites $\quad 34$

3. Regional differences in syllable parameters 34

4. Multidimensional scaling analysis of song parameters 35

5. Type -B syllable shape categories 36

6. Multidimensional scaling analysis of common shape categories 36

7. Multidimensional scaling analysis of spectral contours 37

8. Common song type usage patterns 38

9. Multidimensional scaling analysis of song type usage 39

10. Distance vs. song type dissimilarity 40

11. Song composition of migratory and sedentary colonies $\quad 40$ 


\section{$\underline{\text { Introduction }}$}

Intraspecific variation in phenotypic traits is believed to catalyze speciation, especially when the trait is under divergent sexual and or natural selection pressures (Boughman, 2002; Kirkpatrick and Ravigné, 2002; Lande, 1981; Slabbekoorn and Smith, 2002). Vocal signals are a particularly well-studied example of such a trait, and have often been found to act as an isolating mechanism in bird species and populations (e.g.,Baker and Mewaldt, 1978; Becker, 1982; Catchpole, 1987; Searcy et al., 1981). Thus vocalizations and songs in particular represent an interesting, and promising area of study for anyone interested in phenotypic variation, and its consequences at the organismal, population, and species levels. Moreover because of their complexity, potential to be socially learned, and their propensity to vary among locations or populations, vocalizations have served as a useful model for understanding the complex interplay of genetic and cultural evolution, (e.g., Byers et al., 2010; Deecke et al., 2000; MacDougall - Shackleton and MacDougall - Shackleton, 2001; Slabbekoorn and Smith, 2002). Coming up with an all-encompassing definition of culture has proven to be a difficult and controversial endeavor for anthropologists and biologists alike (Galef, 1992; Kroeber and Kluckhohn, 1952; Laland and Hoppitt, 2003; Whiten et al., 1999). However most would agree that at its core animal culture can be described as group-distinctive behavior pattern(s), which are socially learned and transmitted (Byrne et al., 2004; Heyes and Galef Jr, 1996; Laland and Hoppitt, 2003). Using this definition, vocalizations provide one the most crucial pieces of evidence for the existence of culture in animals, as several species have been shown to have group/area specific vocalization types. Regional vocalization types or "dialects" are shared among local individuals and are consistently distinct from those of individuals in other locations. Dialects can form via two mechanisms, which are not always mutually exclusive; (1) "vocal 
production learning", the ability to create and/or modify vocal signals in response to social interactions (Janik and Slater, 2000), and (2) genetic divergence, in which case isolated populations become increasingly differentiated as a result of genetic drift or in response to differing selective pressures (rev. Boughman and Moss, 2003; Henry et al., 2015; Podos and Warren, 2007). Because of their capacity for horizontal transmission, dialects have been regarded as one of the most important pieces of evidence for the existence of culture in animals. However, caution should be used to determine the mechanism through which dialects arise before asserting whether they are indicative of culture in any given system (Laland and Janik, 2006).

Dialects can also have important consequences on social interactions and individual reproductive success. For example, in several songbird species females preferentially mate with males that sing the local dialect over males with foreign dialects (Baker et al., 1987; Baker et al., 1981b; MacDougall-Shackleton et al., 2002). Additionally, multiple playback studies have shown that male songbirds can distinguish between familiar and foreign males on the basis of their vocalizations, and that they adjust their interactions accordingly (rev. Stoddard, 1996). Mate guarding Australian sea lions can also distinguish between familiar and foreign sounding males, and react more aggressively towards familiar sounding males (Attard et al., 2010).. Thus vocal dialects can have crucial implications for how individuals are perceived and treated, with whom they mate, and their reproductive success.

To date dialects have been found in a variety of avian species, including song birds (e.g., Marler and Tamura, 1962), parrots (e.g.,Wright, 1996), and hummingbirds (e.g.,Gaunt et al., 1994). Notably these are the same lineages of birds that are known to be vocal learners; it is their learning ability that has led to the highly salient regional differences in vocalizations (Baptista and Schuchmann, 1990; Slater, 1989; Wright and Wilkinson, 2001). 
Dialects have also been found in a scattered yet growing list of mammalian taxa including; cetaceans (Ford, 1991; Whitehead, 1998), elephant seals (Le Boeuf and Peterson, 1969), rock hyraxes (Kershenbaum et al., 2012), marmosets (de la Torre and Snowdon, 2009), and two species of bats (Davidson and Wilkinson, 2002; Esser and Schubert, 1998). While a growing number of mammals have been shown to have vocal dialects, in most cases the mechanisms of how these dialects arise are still unclear. To date vocal production learning has only been found in cetaceans, (rev. Janik and Slater, 1997), pinnipeds (rev. Reichmuth and Casey, 2014), elephants (Poole et al., 2005), and bats (Boughman, 1998), so it is likely that variation observed in other mammalian taxa may be due to genetic divergence of the populations rather than learning.

One way to assess the cause of dialects, albeit indirectly, is to examine the pattern of variation across geographical distance. Vocal variation can follow random, clinal, or sharp spatial distributions (Podos and Warren, 2007). Under random spatial variation songs are as likely to be most similar to songs from a nearby location as to a distant location. The opposite is true for the clinal pattern; with this type of variation songs from nearby locations are more alike than songs produced in locations far apart. Thus under clinal vocal variation one would expect to see a positive correlation between song similarity and geographical distance. Because the colonies in this study occupied the same habitat type, if clinal variation is observed it would be suggestive of dialects that arise from genetic divergence. Lastly under sharp spatial variation, vocalizations from each region tend to be markedly different from the surrounding areas, with sharp boundaries in vocalization type usage. Under sharp variation one would expect a negative correlation between distance and song similarity at the micro geographical scale but this relationship would be expected to weaken and disappear with 
distance. The sharp pattern of vocal variation is expected from dialects that originate from vocal production learning.

Part of the reason fewer studies have explored vocal dialects in mammals than in birds is that mammal vocalizations tend to be simple, innate, and inflexible compared to those of birds. Most of the avian species that have been documented to have vocal dialects are also capable of vocal learning, and have intricate multisyllabic vocalizations. The Brazilian freetailed bat (Tadarida brasiliensis) resembles songbirds in that it has exceptionally complex and flexible vocalizations. The relatively high level of vocal intricacy and flexibility in their songs makes these bats likely to exhibit regional variation. The aims of the present study were, to quantify vocal variation in this species at the individual, colonial, and regional levels, to determine if this species has vocal dialects, and to assess whether vocal variation is correlated with geographical distance, which would suggest the mechanism(s) through which the pattern of variation originated. To accomplish these goals I compared acoustical and syntactical features of male songs from six colonies, and then tested for a relationship between vocal variation and geographical distance.

The Brazilian free-tailed bat (Tadarida brasiliensis) is an aerial hawking insectivore from the family Molossidae. Tadarida.brasiliensis's range extends from South America to North America, one of the most common mammals in the south and southwestern United States. Brazilian free-tailed bats are well adapted to living in urban environments, and can be readily seen roosting in man-made structures such as bat houses, bridges, roof tiles, tool sheds etc. (Avila-Flores and Fenton, 2005; Scales and Wilkins, 2007). Males sing from their roost sites during the day with activity peaking about one hour post arrival in the morning, and before emerging to forage in the evening (pers. obs.). As in songbirds, male 
T.brasiliensis, and males of several other bat species, use their songs to attract females and mediate male-male aggression (Bohn et al., In Press. ; Bohn et al., 2008).

The songs of T. brasiliensis are hierarchically organized and composed of four syllables types, which are combined to form phrases whose order and frequency varies from one rendition to the next (Fig. 1). The chirp phrase is composed of two syllable types ("A" and "B") Type B syllables are longer, and have more intricate patterns of frequency modulation than Type A syllables (Bohn et al., 2008). Moreover type B syllables are highly variable among males in a colony, yet remain consistent across renditions sang by each male. Type B syllables are thus better suited to show inter and intra-colony song variation, and so I focused on them as I looked for acoustic variation across regions in this study. To look at syntactical differences among colonies I examined song composition, and the way in which the phrases were ordered. Each uniquely ordered combination of phrases was deemed a song type, and the number and usage of the song types was compared among locations.

\section{Methods}

Brazilian free tailed bats readily roost in human-made structures such as bat houses, buildings, and openings in roofs and tiles. For the present study easily accessible colonies of free-tailed bats were recorded at naturally occurring roost sites in Miami FL, Orlando FL, Jacksonville FL, Quitman GA, College Station TX, recordings were also obtained from a captive colony in Austin TX (Fig.2). These colonies varied in size from tens to thousands of individuals but efforts were made to record only small groups of bats at a time by focusing on isolated subgroups and by placing a plastic tube over the microphone, which created extreme directionality and attenuated sounds from non-focal area. Bats sing and vocalize throughout the day, often at low enough frequencies to be heard with the un-aided ear. Recordings were made from accessible groups of each colony, during the afternoons (2 pm-sunset). At this 
time bats were active but there was no echolocation calls (bats were not flying), which was a problem when recording at night. Songs were recorded using an externally polarized condenser microphone (CM16, Avisoft BioacousticS Berlin Germany) and digitized at 250 $\mathrm{kHz}$ sampling rate using an Avisoft UltrasoundGate hardware (116Hm, Avisoft Bioacoustics) for storage on a personal computer running Avisoft-Recorder software. To examine whether songs vary among geographic location, we focused on two main song components: syllable parameters and song syntax. Male songs were defined as vocalizations that have multiple types of syllables and phrases and are separated by periods of silence of at least $115 \mathrm{~ms}$ (Bohn et al., 2009). Unless otherwise stated all statistical tests were performed using ' $R$ ' statistical software (Ihaka and Gentleman, 1996).

\section{Variation in Syllable Acoustics}

For the comparison of syllable acoustics, five songs were randomly selected for analysis from each of 6-15 males per roost site $($ mean $=11, \mathrm{sd}=4)$ for a total of 70 males and 350 songs. From each song we randomly selected one B so that no B syllables were from the same song. To examine inter-colony differences in syllable acoustics we measured, min, max, and peak frequency of type B syllables from spectral contours created using SIGNAL sound analysis software (version 5.0, Engineering Design, Belmont, Massachusetts). Duration was measured from oscillograms which were also created using SIGNAL. Nested mixed ANOVAs with individual bats as random factors nested within colony and colony nested within region (east or west) were used to test for regional differences in syllable acoustic parameters, with Bonferroni corrections $($ alpha $=0.0083)$. Restricted maximum likelihood was used to calculate variance component estimates among regions, among colonies, among bats, and within bats. These syllable measurements were then averaged for each male, and the averages used in a multidimensional scaling (MDS) analysis to see how 
the males grouped based on similarity of the acoustic parameters. Linear discriminant analyses were then used to test whether bats could be correctly assigned to their colony, or region of origin based on the six syllable parameters measured. When testing to see whether songs could be correctly categorized as eastern or western, data from all Florida and Georgia colonies were pooled to form the eastern group, while the Austin and College Station data were combined to form the western group.

\section{Spectro-temporal Variation}

To analyze the spectro-temporal variation in type B syllables, I converted them into spectral contours using SIGNAL. Spectral contours are frequency functions that depict a signal's dominant frequency (the one with the most energy) at each time point. Spectral contours are thus great when one wants to look at how a signal's frequency varies over time. I normalized all the contours to be of equal length by compressing and stretching some of them with interpolation until they all were $17 \mathrm{~ms}$ in duration, which was their average length $(\bar{x}=17 \mathrm{~ms}, \mathrm{sd}=4 \mathrm{~ms})$. I later averaged the contours by bat, so that each bat's type B syllable shape was represented by the average of 5 of its syllables. The aforementioned transformation resulted in equal-sized vectors that conveyed the pattern of frequency modulation of the type B syllable. A matrix of Euclidian distances between contours was then constructed from these averaged vectors using the "dist" package in $\mathrm{R}$, and used in multidimensional scaling analysis. Additionally a hierarchical clustering analysis was performed based on the distance matrix of the contours. 


\section{Variation in Song Syntax}

To examine variation in song syntax I randomly selected one hundred songs from each location and visually categorized them into song types using their phrase order (i.e., their syntax). Each song type was a unique sequence of phrases, excluding consecutive trills or buzzes. I then calculated the proportion of songs $\mathrm{P}(\mathrm{t})$ that belonged to each song type, for each location : $\mathrm{P}(\mathrm{t})=\mathrm{n}(\mathrm{t}) / 100$ where $\mathrm{n}(\mathrm{t})$ is the number of songs of type $\mathrm{t}$ for a particular location. The analysis revealed four common song types that were recorded at almost all locations, and accounted for the majority of song types encountered. I used contingency tables and chi-square tests to determine if the number of common and rare songs differed among locations, and to determine whether usage of the common song types differed from one location to the next. I then calculated the sum of squared differences in song type usage $\Delta$ between locations

$$
\Delta(a, b)=\sum_{t}^{T}\left(P_{a}(t)-P_{b}(t)\right)^{2}
$$

where $\Delta(\mathrm{a}, \mathrm{b})$ is sum of square differences between locations a and $\mathrm{b}, \mathrm{P}_{\mathrm{a}}(\mathrm{t})$ and $\mathrm{P}_{\mathrm{b}}(\mathrm{t})$ are the proportions of song type $\mathrm{t}$ at locations $\mathrm{a}$ and $\mathrm{b}$ respectively, and $\mathrm{T}$ is the total number of song types found. The calculation resulted in a measure of syntactic similarity between locations, with sites that had the most similar patterns of song type usage having the lowest scores and sites that were more dissimilar having higher scores. I used those values to create a matrix of dissimilarity among the six locations, which was used for multi-dimensional scaling analysis. 


\section{Variation and Distance}

Mantel tests (Mantel, 1967; Oksanen et al., 2007) were used to asses whether the observed variation correlated with geographical distance between locations. In total three different mantel tests were performed. The first Mantel test was done using a matrix of geographical distance between males and a matrix of eucladian distances using the male's average syllable parameters. Similarly to test whether there was a correlation between spectro-temporal variation and distance, a Mantel test was performed on a distance matrix based on syllable contours and a matrix of geographical distances. Lastly to determine if differences in song syntax were correlated with geographical distances, I used Mantel test on a matrix of song type usage dissimilarity between colonies, and a matrix of geographical distances. In all instances dissimilarity between an entity and itself was zero, and geographic distance between males of the same colony was also zero.

\section{Variation and Migration}

To test whether there was syntactical variation in the songs that could be attributed to differences in migratory behavior I pooled the one hundred songs from both Austin and College Station to represent a sample from migratory populations, and one hundred songs each from Miami and Jacksonville colonies to represent a non migratory population sample, for a total of 400 songs. I then used T-tests to determine whether the total number of phrases

per song, or the number of different phrase types per song differed between the migratory and sedentary populations. I used the aforementioned parameters as measures of complexity; longer songs (with more total phrases) were considered more complex than shorter ones, and songs, which had higher number of distinct phrase types, were deemed more complex than songs with fewer phrase types (more repetition). Additionally I compared the number of song types found in the samples from both regions, and determined whether the proportion of 
songs containing buzz or trills differed between the migratory and sedentary populations. I chose to focus on the songs with trills and buzzes because these phrase types resemble the irritation vocalizations these bats emit when engaged in antagonistic interactions (Bohn et al., 2008) and so if sedentary populations really are under increased intra-sexual selection, they would be expected to use trills and buzzes more often.

\section{$\underline{\text { Results }}$}

\section{Variation in Syllable Acoustics}

Each of the six syllable measurements differed among individuals within colonies, and within-bat variation was relatively low for all six acoustic measurements (Table. 1). Colonies within each region did not differ significantly in any of the parameters measured (Table 1). However there were several regional level differences. Colonies in the east differed significantly from those in the west in terms of maximum frequency and beginning frequency. Additionally there were marked regional differences in syllable duration and ending frequency, however these were marginally non statistically significant at an alpha of 0.008 ( $\mathrm{p}=0.009$ and 0.01 respectively). In general, males from eastern colonies produced type-B syllables, which were longer in duration and lower in frequency than those produced by their western counterparts (Fig.3). Multidimensional scaling analysis (MDS) of the syllable parameters confirms a salient distinction, between syllables of males from the western and eastern regions of this study (Fig.4). Subsequent linear discriminant analysis showed that males were correctly assigned to their colony of origin $36 \%$ of the time. However accuracy improved considerably when assigning males to their correct region of origin, $86 \%$ of males were correctly assigned to either the western or eastern group on the basis of their acoustic parameters of their Type-B syllables. 


\section{Spectro-temporal Variation}

Hierarchical clustering of the syllable contours revealed that these fall into six type-B syllable shape categories (Figure 5). These six syllable shapes were not equally common, half of the shape categories together $(\mathrm{a}, \mathrm{d}, \& \mathrm{e})$ accounted for $81 \%$ of the bats, while the other three categories (b,c,\&f) combined accounted for the remaining 19\% (Table 3). The most common syllable shapes $(\mathrm{a}, \mathrm{d}, \& \mathrm{f})$ were seen at all locations, while the other shapes were present at some but not all locations (Table 3). Bats belonging to the same shape category did not differentiate by colony of origin (Figure 6). Interestingly despite the fact that some of the syllable shapes were present at all locations, and that they seem to be evenly distributed. Multidimensional scaling analysis revealed marked distinctions between the eastern colonies and some differentiation between eastern and western bats (Figure 7).

\section{Variation in Song Syntax}

The 100 song sample from each location yielded a total of 600 songs and 46 distinct song types, these song types were far from being equally common, but rather the three song types most frequently observed, accounted for $65 \%$ of the songs recorded while the 30 least common song types combined accounted for only $9 \%$ of songs (Table .2) .The three most common song types made up between $49 \%$ and $68 \%$ percent of songs recorded at each location, and usage of these ubiquitous songs differed among locations $\left(p<.0001, X^{2}=142\right.$, $\mathrm{df}=15)($ Figure 8$)$ and among regions $\left(\mathrm{p}<.0001, \mathrm{X}^{2}=20, \mathrm{df}=3\right)$. Multidimensional scaling analysis based on differences in song type usage among locations did not result in any obvious grouping pattern (Figure 9). Songs of colonies that were closer together do not seem to be more similar to each other than colonies that were further apart (Figure 10). 


\section{Variation and Distance}

The variation observed in Type-B syllable parameters showed a weak positive correlation with geographical distance (Mantel 9999 permutations, $r=0.21, p=0.0001$ ). Meanwhile the variation in the syllable contour shapes was not correlated with geographic distance (Mantel 9999, $\mathrm{r}=-0.007, \mathrm{p}=0.64$ ), .The lack of correlation with distance observed is consistent with the hierarchical clustering analysis, which shows that B syllables fall into one of six categories which appear to be evenly distributed across the locations in this study. Similarly there was no significant correlation between variation in song type usage and geographical distance (Mantel 9999 permutations, $r=0.13, p=0.27$ ). The lack of correlation between the syntactical variation observed and geographic distance corroborates the MDS analysis, which showed that the locations, which were the closest, were not necessarily the most similar in song type usage.

\section{Variation and Migration}

Songs of males from migratory, and sedentary populations did not differ significantly in the average total number of phrases per song $(t=0.69, p=0.49)$, nor in the number of different phrases per song $(\mathrm{t}=1.4, \mathrm{p}=0.18)$ (Figure 11$)$. The migratory and non-migratory populations did not differ in their proportion of songs with trills $\left(x^{2}=3.4, p=0.07\right)$. However

the two populations did differ in the proportion of songs with buzzes $\left(x^{2}=16.34, p=0.0001\right)$, with migratory populations having $54 \%$ of songs which contained a buzz, while in sedentary populations $73 \%$ of songs contained at least one buzz. After visually categorizing all the songs by song types, I found 39 distinct song types in the sample of songs from the migratory populations, and 37 distinct types in the two hundred songs from the sedentary populations. 


\section{$\underline{\text { Discussion }}$}

This study describes three classes of geographical variation in the songs of male Tadarida brasiliensis at various levels. First I confirm that the type b syllable structure is stereotyped within males, and that males within a colony vary widely in their shape of their type-B syllables. The type-B syllables can be categorized into six syllable shapes based on their pattern of frequency modulation. The six types-B syllable shape categories differ significantly from each other in all the acoustic parameters measured, and accounted for up to $75 \%$ of the variation observed in some cases. The large amount of variation in type-B syllable shape suggests that the type-B syllable may play a role in individual recognition. Vocal recognition occurs in several mammalian species (e.g. McComb et al., 2000; Rendall et al., 1996; Sayigh et al., 1999), including several species of bats (Boughman and Wilkinson, 1998; Masters et al., 1995; Yovel et al., 2009). Moreover Brazilian free-tailed bats have been shown to be able to use vocal signals for individual recognition in the context of motheroffspring reunions (e.g., Balcombe, 1990; Balcombe and McCracken, 1992), so it is not unlikely that vocal recognition may be occurring based on B-syllable parameters. However, further work will need to be done to explicitly test whether B-syllables do indeed serve as individual signatures. Preliminary familiar/unfamiliar playback experiments aimed at freeroosting males did not elicit enough robust responses for analysis. Songs are known to be used for mate attraction, and in the defense of the immediate roosting space (Bohn et al., 2008), however males in this study did not engage in the agonistic countersigning that is typical of their passerine counterparts (Catchpole and Slater, 2003) and field conditions prevented direct observational measurements of other possible behavioral responses to playback stimuli. Future work may be better aimed at the ability of females to perceive differences in type-B syllables and its effect on sexual selection. 
Analysis of the geographical variation in syllable parameters took place at both the micro and macro geographical scales. Over comparatively short distances (within regions) type-B syllables from males of different colonies did not significantly differ from one another in terms of the acoustic parameters measured. However over larger scales (among regions), type-B syllables differed significantly in maximum frequency and beginning frequency and showed salient distinctions in syllable durations. Males from colonies belonging to the eastern region in this study, produced type $-\mathrm{B}$ syllables that were longer in duration and lower in frequency than those produced by males from the western colonies. Linear discriminant analysis based on each bat's average type-B syllable parameters, correctly classified $85 \%$ of the bats in this study as belonging to eastern or western regions. Largescale patterns of geographical variation in vocalizations have been found in several other species of birds (rev. Mundinger, 1982) and mammals (e.g., Slobodchikoff and Coast, 1980; Somers, 1973; Thomas and Stirling, 1983) and are often the result of genetic differentiation between the populations. Genetic divergence is especially likely to be the driving factor of macro geographic variation in vocalizations when the large distances act as a barrier to gene flow, or when there are other geographic barriers that impede genetic mixing. While the populations in this study are not completely isolated from each other, genetic divergence cannot be ruled out as a driving factor of the variation seen in syllable structure, especially since this variation was correlated (albeit weakly) with geographic distance.

The observed distinction in type-B syllable structure is consistent with several other behavioral and morphological differences between eastern and western populations of Tadarida brasiliensis. For instance western populations tend to roost in caves and man-made structures in numbers that can reach several millions (Davis et al., 1962a) while eastern populations are found occupying mainly man-made structures and roosting in groups from 
two to a few thousand individuals (Bain, 1981). Moreover, while western populations are migratory and fly to Mexico during the winter months, eastern populations do not migrate but rather undergo torpor (LaVal, 1973) or in warmer climates like Florida, remain active during the winter (Kiser, 1996). The behavioral differences along with some differences in skull and forearm length has led these two populations to be classified as two separate subspecies, with eastern ones being named T. b. cynocephali and western ones T.b. mexicana (Barbour and Davis, 1969; Carter, 1962; Owen et al., 1990). Nonetheless these defining characteristics show substantial plasticity and some populations exhibit traits inconsistent with those of their subspecies (rev. Russell and McCracken, 2006). Moreover several studies looking at genetic structure in these populations have found no evidence to support distinguishing eastern and western populations as separate subspecies (McCracken and Gassel, 1997; Russell and McCracken, 2006). While the genetic relatedness of the subject populations of this work was not determined in this study, it seems unlikely such analysis would reveal any population structure. A recent large-scale study of behaviorally and geographically distinct populations in the southwestern United States revealed no significant population structure (Russell et al., 2005). Thus I would not expect populations in Florida, which span much shorter distances, to have higher levels of genetic divergence. Other studies have also shown that T. brasiliensis in Florida are genetically very similar to those in Texas. In their 1997 study McCracken \& Gassel obtained samples from roost sites in Florida that were less than $100 \mathrm{~km}$ from the colonies I studied, and compared them to bats from Texas and California. Based on data from 22 different loci, McCracken and Gassel found high genetic similarity between the Florida bats and those of Texas and California. Furthermore (Russell and McCracken, 2006) looked at mtDNA control region sequence variation in the north American mainland subspecies of $T$. brasiliensis, including Florida and Texas bats from roosts very near the ones studied here and 
found little differentiation between the subspecies. The authors concluded that there is a large amount of gene flow between the eastern and western populations and as such, separating out T. b. cynocephala as a distinct subspecies from $T$. . mexicana did not make sense based on their data.

Analysis of the spectro- temporal variation revealed that the males' type-B syllables fall into one of six general shape categories, which were observed at nearly all locations. While there is considerable variation among males in each shape category, they do not correspond to differences among locations, but rather differences between individual males. The B syllable shapes may play a bigger role in distinguishing between males than in differentiating males from different colonies. Nonetheless eastern colonies showed considerable differentiation based on the shape of their type syllables. One possible explanation for this may be that while the shape categories themselves do not differ between locations, the frequencies with which they appear may be different from one location to the next. For instance if location 1 is mostly composed of males with shape "d" syllables and location 2 has mainly males that produce shape "e" syllables, this would cause a differentiation between the colonies. Such patterns were not obviously apparent in the data, and unfortunately small sample sizes prevented me from explicitly testing whether this was indeed occurring.

Syntactical analysis of male songs revealed significant differences in song type usage among locations. While the most common song types were present at all sites studied, the frequencies with which these song types were used varied from one location to the next, resulting in distinct patterns of song type usage. Additionally some song types were only recorded at a single colony, indicating that they may be site-specific songs. The variation in song type usage observed was not correlated with geographical distance, but rather colonies 
seem to be distinct dialectical entities. The colonies were as likely to have as similar song type usage patterns to colonies that are close together as to those farther apart. The lack of a clinal pattern of variation in song type usage, suggests that the differentiation is likely not being driven by genetic divergence between the populations. One possible reason for the pattern of variation observed may be that the colonies in this study were relative far apart, and may have lack sufficient inter-colony social interaction for the different dialects to be influenced by one another. The two geographically closest colonies in this study were Austin and College Station, which are $\sim 140 \mathrm{~km}$ apart, and the furthest ones were Austin and Miami which are $\sim 1800 \mathrm{~km}$ away from each other. While Tadarida Brasiliensis are capable of flying long distances they typically stay within $50 \mathrm{~km}$ from their roost sites while foraging (Davis et al., 1962b), so bats from these colonies do not come into contact with each other on a daily basis. Without routine contact with males from other colonies we would expect little or no foreign influence on male songs. Similar patterns of syntactical dialects, which lack a correlation with geographical distance over large scales have been found in other species, including the sage sparrow (Wiens, 1982) and rock hyraxes (Kershenbaum et al., 2012), in the above examples the lack of correlation of dialectical patterns over large distance have also been attributed to reduced mobility and to lack of interaction between individuals belonging to different dialectical groups and do not come into contact with each other. 
To summarize, here I report finding multiple patterns of variation in the songs of male free-tailed bats at various scales. First, there is wide range regional variation in syllable acoustic parameters, which is weakly correlated with distance. Second, at shorter geographic distances, colonies do not differentiate based on acoustic parameters of the type-B syllable, but differ instead in the type-B syllable shapes (patterns of frequency modulation), and in the patterns of song type usage. Neither variation in syllable shape, nor in song type usage, correlate with geographic distance. Third, at the colony level, there is large variation in typeB syllable acoustic parameters between bats, and relatively low levels of variation within bats. Aside from genetic divergence and vocal learning, other factors that could potentially drive the acoustic variation observed are; migratory behavior, and habitat structure. Bellow I discuss each of these and comment on their potential influence on the variation observed.

One potential contributing factor to the differences in song between eastern and western bats is that males may be under different selective pressures as a result of differing migratory behavior. In birds it has been hypothesized that males of species or populations, which migrate, are under different selective pressures than sedentary ones, and that this is a driver of differences in song structure. The idea being that migratory males are under stronger sexual selection because they have less time to establish a territory and attract a mate, while sedentary males are more strongly affected by intra sexual selection because they have to protect and maintain territories for longer periods of time (Catchpole, 1982). Female preferences in songbirds are typically for bigger repertoires and increased complexity (Catchpole, 1980; Soma and Garamszegi, 2011), while aggressive male-male interactions favor shorter more stereotyped songs (Collins, 2004), thus under this hypothesis migrating males (those from the western populations) would be predicted to have larger repertoire and sing longer, more complex songs. However my analysis of syntax and song composition of 
eastern and western populations showed that this is not the case in this species. Migrating and sedentary populations in this study did not differ significantly in the total number of phrases used per song, the number of different phrases used per song, nor in the number of trills. Moreover the number of distinct song types recorded in the sample of two hundred randomly selected western songs did not differ substantially from the number of distinct song types recorded in the two hundred eastern songs (39-37 respectively). In short the hypothesis that migratory populations have lager repertoires and sing longer more complex songs was not supported by my data. There are a couple of potential reasons why this may be the case, some of them are; 1) this hypothesis may not be applicable to $T$. brasiliensis because of differences in life histories between these bats and the passerines for which the hypothesis was intended, 2) the chosen indicators of complexity may not fully represent the complexity of the songs. The hypothesis that males from migratory populations have larger repertoires, and sing longer more complex songs, was developed with songbirds in mind, and it may not be appropriate to extend it to T. brasiliensis. This hypothesis is founded in two main points neither of which apply to T. brasiliensis: I) migratory males have less time to establish territories and attract mates, II) sedentary males have to protect territories for longer periods of time. Unlike most songbirds, T. brasiliensis males do not establish nor defend foraging territories, but rather defend their immediate roosting space and attract females there, migratory behavior likely has no effect on where a male roosts each night in relation to the other individuals. Moreover while there is large variation in length of roost usage, in general specific roosting spots are ephemeral, and males change locations after a few nights or a couple of weeks sometimes with part or all of the group changing roosting locations entirely. Given that the spaces that are actually defended by $T$. brasiliensis males are constantly changing in both migratory and non-migratory populations, the principle that sedentary males 
have to defend their territory for longer periods of time does not hold true in this species. Additionally it is possible the measures of complexity used in this study (number of total phrases/ song, number of different phrases /song, number of song types, phrase usage) may not have been enough to characterize the complexity of the songs. For instance while I counted the number of phrases I did not account for the length of each phrase which showed considerable variation and contributed to overall song length. Lastly it is worth noting that while the migratory and sedentary populations did not differ in song complexity, the sedentary population did have a higher proportion of buzz containing songs. Buzzes are structurally similar to irritation calls produced by $T$. brasiliensis in antagonistic interactions, and a higher number of buzzes could indeed be correlated with increased aggressive interactions as predicted by this hypothesis, however further work would need to be done to confirm this.

Another important factor that can affect the structure of vocal signals is habitat type and environmental conditions. Vocalizations, like all signals must be transmitted from the sender to the receiver, and in the process are subject to environmental and habitat dependent factors that affect their patterns of degradation, attenuation, scattering, and more (Marten and Marler, 1977; Wiley and Richards, 1978). It is thus not surprising that habitat can impose significant selective pressure on the structure of vocalizations (Boncoraglio and Saino, 2007; Morton, 1975) and often this lead songs from populations that live in different habitat types to have different acoustic properties (e.g.Baker, 2006; Hunter and Krebs, 1979; Nicholls and Goldizen, 2006; Patten et al., 2004). However habitat type is not a likely driver of the geographic variation observed in this study, as all colonies recorded were in similar urban habitats and so the males' songs are expected to be under similar environmental pressures. 
This study adds to the growing body of literature examining complexity in mammalian vocalization, and is the first to compare $T$. brasiliensis songs across a geographical range. These differences in vocalizations may have important implications for social interactions and the reproductive fitness of both resident and foreign males. Similar consequences have been found in other species; for example in the greater spear nosed bat group distinctive calls promote group cohesion when foraging (Boughman, 1998) and recognition of the local isolation call dialect helps reduce male-male aggression in the greater sac-winged bat (Knörnschild et al., 2012). Additionally in many bird species, females prefer to mate with males that sing their home dialects (Baker et al., 1987; Baker et al., 1981a) and male white-crown sparrows with foreign dialects have been found to have lower paternity and higher parasite loads (MacDougall-Shackleton et al., 2002). Therefore vocal dialects have the potential to be a powerful force driving sexual selection, and may ultimately contribute to population divergence, reproductive isolation and speciation (Slabbekoorn and Smith, 2002).

The existence of vocal variation in this species also contributes to the comparative study of the evolution of dialects, and language. The Brazilian free-tailed bat has a markedly different life history than most available models to date. For instance, unlike avian song learners, young T. brasiliensis are raised solely by their mothers in maternity colonies (Davis et al., 1962b; Kunz and Robson, 1995), and so are unlikely to be exposed to songs at an early age, a crucial requirement for song learning in many bird species (rev. Beecher and Brenowitz, 2005). The existence of vocal dialects in this species is highly suggestive of vocal learning, a widely accepted prerequisite to language acquisition. To date, the vast majority of comparative language studies have used songbirds as model organisms due to the logistical ease of studying these diurnal, territorial species; and to the similarities between these taxa. 
Both humans and song birds require auditory sensory feedback for vocal learning (Brainard and Doupe, 2000), like humans some song bird species have sensitive periods during which most new vocalizations are learned (Fitch, 2000), both have babbling, sub-song phases during which vocalizations are practiced and learned, and the two taxa have a similar neural circuitry to support the vocal systems. Adding the Brazilian free-tailed bat as a model species for to this body of research would not only provide additional data for comparative studies, but the closer phylogenetic relationship to humans may result in a higher number of homologous mechanisms, pathways and structures.

In short, this study describes several patterns of vocal variation at multiple spatial scales in the free-tailed bat T.brasiliensis. Colonies in the south and southeastern United States exhibit regional variation in songs in terms of acoustical, spectro-temporal, and syntactical parameters. Furthermore the variation observed leads to vocal dialects, which are likely to be formed from both genetic and learned mechanisms. At the macro geographical level, colonies from eastern and western regions of this study differed in song acoustic parameters in ways typical of variation brought about by genetic divergence. Meanwhile at shorter spatial scales colonies differed in both the shape of type B syllables and in their patterns of song type usage. The spectro-temporal, and syntactical variation observed was not correlated with geographic distance between locations, and is suggestive of a role of vocal learning in dialect formation. 


\section{$\underline{\text { References }}$}

Attard, M.R., Pitcher, B.J., Charrier, I., Ahonen, H., Harcourt, R.G., 2010. Vocal discrimination in mate guarding male Australian sea lions: familiarity breeds contempt. Ethology 116, 704-712.

Avila-Flores, R., Fenton, M.B., 2005. Use of spatial features by foraging insectivorous bats in a large urban landscape. Journal of Mammalogy 86, 1193-1204.

Bain, J.R., 1981. Roosting ecology of three Florida bats: Nycticeius humeralis, Myotis austroriparius, and Tadarida brasiliensis.

Baker, M.C., 2006. Differentiation of mating vocalizations in birds: acoustic features in mainland and island populations and evidence of habitat-dependent selection on songs. Ethology 112, 757-771.

Baker, M.C., Bjerke, T.K., Lampe, H.U., Espmark, Y.O., 1987. Sexual response of female yellowhammers to differences in regional song dialects and repertoire sizes. Animal Behaviour 35, 395-401.

Baker, M.C., Mewaldt, L.R., 1978. Song dialects as barriers to dispersal in white-crowned sparrows, Zonotrichia leucophrys nuttalli. Evolution, 712-722.

Baker, M.C., Spitler-Nabors, K.J., Bradley, D.C., 1981a. Early experience determines song dialect responsiveness of female sparrows. Science 214, 819-821.

Baker, M.C., Thompson, D.B., Sherman, G.L., Cunningham, M.A., 1981b. The role of male vs male interactions in maintaining population dialect structure. Behavioral Ecology and Sociobiology 8, 65-69.

Balcombe, J.P., 1990. Vocal recognition of pups by mother Mexican free-tailed bats, $<\mathrm{i}>$ Tadarida brasiliensis mexicana $</ \mathrm{i}>$. Animal Behaviour 39, 960-966.

Balcombe, J.P., McCracken, G.F., 1992. VOCAL RECOGNITION IN MEXICAN FREETAILED BATS - DO PUPS RECOGNIZE MOTHERS. Animal Behaviour 43, 79-87.

Baptista, L.F., Schuchmann, K.L., 1990. Song learning in the Anna hummingbird (Calypte anna). Ethology 84, 15-26. 
Barbour, R.W., Davis, W.H., 1969. Bats of America. 286 p. Univ. Press Ky., Lexington.

Becker, P.H., 1982. The coding of species-specific characteristics in bird sounds. Acoustic communication in birds 1, 213-252.

Beecher, M.D., Brenowitz, E.A., 2005. Functional aspects of song learning in songbirds. Trends in Ecology \& Evolution 20, 143-149.

Bohn, K.M., Montiel-Reyes, F., Salazar, I.A., In Press. . The complex songs of two molossid species. Sociality in Bats

Bohn, K.M., Schmidt-French, B., Ma, S.T., Pollak, G.D., 2008. Syllable acoustics, temporal patterns, and call composition vary with behavioral context in Mexican free-tailed bats. Journal of the Acoustical Society of America 124, 1838-1848.

Bohn, K.M., Schmidt-French, B., Schwartz, C., Smotherman, M., Pollak, G.D., 2009. Versatility and stereotypy of free-tailed bat songs. PLoS One 4, e6746.

Boncoraglio, G., Saino, N., 2007. Habitat structure and the evolution of bird song: a metaanalysis of the evidence for the acoustic adaptation hypothesis. Functional Ecology 21, 134142.

Boughman, J.W., 1998. Vocal learning by greater spear-nosed bats. Proceedings of the Royal Society B-Biological Sciences 265, 227-233.

Boughman, J.W., 2002. How sensory drive can promote speciation. Trends in ecology \& Evolution 17, 571-577.

Boughman, J.W., Moss, C.F., 2003. Social sounds: vocal learning and development of mammal and bird calls, Acoustic communication. Springer, pp. 138-224.

Boughman, J.W., Wilkinson, G.S., 1998. Greater spear-nosed bats discriminate group mates by vocalizations. Animal Behaviour 55, 1717-1732.

Brainard, M.S., Doupe, A.J., 2000. Auditory feedback in learning and maintenance of vocal behaviour. Nature Reviews Neuroscience 1, 31-40. 
Byers, B.E., Belinsky, K.L., Bentley, R.A., 2010. Independent Cultural Evolution of Two Song Traditions in the Chestnut-Sided Warbler. The American Naturalist 176, 476-489.

Byrne, R.W., Barnard, P.J., Davidson, I., Janik, V.M., McGrew, W.C., Miklósi, Á., Wiessner, P., 2004. Understanding culture across species. Trends in cognitive sciences 8 , 341-346.

Carter, D.C., 1962. The systematic status of the bat Tadarida brasiliensis (I. Geoffroy) and its related mainland forms.

Catchpole, C., 1982. The evolution of bird sounds in relation to mating and spacing behavior. Acoustic communication in birds, 297-317.

Catchpole, C.K., 1980. Sexual Selection and the Evolution of Complex Songs Among European Warblers of the Genus Acr Ocephal Us. Behaviour 74, 149-165.

Catchpole, C.K., 1987. Bird song, sexual selection and female choice. Trends in Ecology \& Evolution 2, 94-97.

Catchpole, C.K., Slater, P.J., 2003. Bird song: biological themes and variations. Cambridge university press.

Collins, S., 2004. Vocal fighting and flirting: the functions of birdsong. Nature's music: the science of birdsong, 39-79.

Davidson, S.M., Wilkinson, G.S., 2002. Geographic and individual variation in vocalizations by male Saccopteryx bilineata (Chiroptera: Emballonuridae). Journal of Mammalogy 83, 526-535.

Davis, R.B., Herreid, C.F., Short, H.L., 1962a. Mexican free-tailed bats in Texas. Ecological Monographs 32, 311-346.

Davis, R.B., Herreid, C.F., Short, H.L., 1962b. Mexican free-tailed bats in Texas. Ecological Monographs, 311-346.

de la Torre, S., Snowdon, C.T., 2009. Dialects in pygmy marmosets? Population variation in call structure. American Journal of Primatology 71, 333-342. 
Deecke, V.B., Ford, J.K., Spong, P., 2000. Dialect change in resident killer whales: implications for vocal learning and cultural transmission. Animal Behaviour 60, 629-638.

Esser, K.-H., Schubert, J., 1998. Vocal dialects in the lesser spear-nosed bat Phyllostomus discolor. Naturwissenschaften 85, 347-349.

Fitch, W., 2000. The evolution of speech: a comparative review. Trends in cognitive sciences $4,258-267$.

Ford, J.K., 1991. Vocal traditions among resident killer whales (Orcinus orca) in coastal waters of British Columbia. Canadian journal of zoology 69, 1454-1483.

Galef, B.G., 1992. The question of animal culture. Human Nature 3, 157-178.

Gaunt, S.L., Baptista, L.F., Sánchez, J.E., Hernandez, D., 1994. Song learning as evidenced from song sharing in two hummingbird species (Colibri coruscans and C. thalassinus). The Auk, 87-103.

Henry, L., Barbu, S., Lemasson, A., Hausberger, M., 2015. Dialects in animals: Evidence, development and potential functions. Animal Behavior and Cognition 2, 132-155.

Heyes, C.M., Galef Jr, B.G., 1996. Social learning in animals: the roots of culture. Elsevier.

Hunter, M.L., Krebs, J.R., 1979. Geographical variation in the song of the great tit (Parus major) in relation to ecological factors. The Journal of Animal Ecology, 759-785.

Ihaka, R., Gentleman, R., 1996. R: a language for data analysis and graphics. Journal of computational and graphical statistics 5, 299-314.

Janik, V.M., Slater, P.J., 2000. The different roles of social learning in vocal communication. Animal Behaviour 60, 1-11.

Janik, V.M., Slater, P.J.B., 1997. Vocal learning in mammals, in: Slater, P.J.B., Rosenblatt, J.S., Snowdon, C.T., Milinski, M. (Eds.), Advances in the Study of Behavior, Vol 26, pp. 5999. 
Kershenbaum, A., Ilany, A., Blaustein, L., Geffen, E., 2012. Syntactic structure and geographical dialects in the songs of male rock hyraxes. Proceedings of the Royal Society of London B: Biological Sciences 279, 2974-2981.

Kirkpatrick, M., Ravigné, V., 2002. Speciation by natural and sexual selection: models and experiments. The American Naturalist 159, S22-S35.

Kiser, W., 1996. Observations of a winter colony of LeConte's free-tailed bats Tadarida brasiliensis cynocephala in Lee Co. Alabama. Bat Research News 37, 116.

Knörnschild, M., Nagy, M., Metz, M., Mayer, F., von Helversen, O., 2012. Learned vocal group signatures in the polygynous bat Saccopteryx bilineata. Animal Behaviour 84, 761769.

Kroeber, A.L., Kluckhohn, C., 1952. Culture: A critical review of concepts and definitions. Papers. Peabody Museum of Archaeology \& Ethnology, Harvard University.

Kunz, T.H., Robson, S.K., 1995. Postnatal growth and development in the Mexican freetailed bat (Tadarida brasiliensis mexicana): birth size, growth rates, and age estimation. Journal of Mammalogy 76, 769-783.

Laland, K.N., Hoppitt, W., 2003. Do animals have culture? Evolutionary Anthropology: Issues, News, and Reviews 12, 150-159.

Laland, K.N., Janik, V.M., 2006. The animal cultures debate. Trends in Ecology \& Evolution 21, 542-547.

Lande, R., 1981. Models of speciation by sexual selection on polygenic traits. Proceedings of the National Academy of Sciences 78, 3721-3725.

LaVal, R.K., 1973. Observations on the biology of Tadarida brasiliensis cynocephala in southeastern Louisiana. American Midland Naturalist, 112-120.

Le Boeuf, B.J., Peterson, R.S., 1969. Dialects in elephant seals. Science 166, 1654-1656.

MacDougall-Shackleton, E.A., Derryberry, E.P., Hahn, T.P., 2002. Nonlocal male mountain white-crowned sparrows have lower paternity and higher parasite loads than males singing local dialect. Behavioral Ecology 13, 682-689. 
MacDougall-Shackleton, E.A., MacDougall-Shackleton, S.A., 2001. Cultural and genetic evolution in mountain white-crowned sparrows: Song dialects are associated with population structure. Evolution 55, 2568-2575.

Mantel, N., 1967. The detection of disease clustering and a generalized regression approach. Cancer research 27, 209-220.

Marler, P., Tamura, M., 1962. Song" dialects" in three populations of White-crowned Sparrows. Condor, 368-377.

Marten, K., Marler, P., 1977. Sound transmission and its significance for animal vocalization. Behavioral ecology and sociobiology 2, 271-290.

Masters, W.M., Raver, K.A.S., Kazial, K.A., 1995. SONAR SIGNALS OF BIG BROWN BATS, EPTESICUS-FUSCUS, CONTAIN INFORMATION ABOUT INDIVIDUAL IDENTITY, AGE AND FAMILY AFFILIATION. Animal Behaviour 50, 1243-1260.

McComb, K., Moss, C., Sayialel, S., Baker, L., 2000. Unusually extensive networks of vocal recognition in African elephants. Animal Behaviour 59, 1103-1109.

McCracken, G.F., Gassel, M.F., 1997. Genetic structure in migratory and nonmigratory populations of Brazilian free-tailed bats. Journal of Mammalogy 78, 348-357.

Morton, E.S., 1975. Ecological sources of selection on avian sounds. American Naturalist, 17-34.

Mundinger, P.C., 1982. Microgeographic and macrogeographic variation in the acquired vocalizations of birds. Acoustic communication in birds 2, 147-208.

Nicholls, J.A., Goldizen, A.W., 2006. Habitat type and density influence vocal signal design in satin bowerbirds. Journal of Animal Ecology 75, 549-558.

Owen, R.D., Chesser, R.K., Carter, D.C., 1990. The systematic status of Tadarida brasiliensis cynocephala and Antillean members of the Tadarida brasiliensis group, with comments on the generic name Rhizomops Legendre. Texas Tech University Press.

Patten, M.A., Rotenberry, J.T., Zuk, M., 2004. Habitat selection, acoustic adaptation, and the evolution of reproductive isolation. Evolution 58, 2144-2155. 
Podos, J., Warren, P.S., 2007. The evolution of geographic variation in birdsong. Advances in the Study of Behavior 37, 403-458.

Poole, J.H., Tyack, P.L., Stoeger-Horwath, A.S., Watwood, S., 2005. Animal behaviour: elephants are capable of vocal learning. Nature 434, 455-456.

Reichmuth, C., Casey, C., 2014. Vocal learning in seals, sea lions, and walruses. Current opinion in neurobiology $28,66-71$.

Rendall, D., Rodman, P.S., Emond, R.E., 1996. Vocal recognition of individuals and kin in free-ranging rhesus monkeys. Animal Behaviour 51, 1007-1015.

Russell, A.L., McCracken, G.F., 2006. Population genetic structuring of very large populations: The Brazilian free-tailed bat Tadarida brasiliensis. Oxford University Press, New York, pp. 227-247.

Russell, A.L., Medellin, R., McCracken, G., 2005. Genetic variation and migration in the Mexican free-tailed bat (Tadarida brasiliensis mexicana). Molecular Ecology 14, 2207-2222.

Sayigh, L.S., Tyack, P.L., Wells, R.S., Solow, A.R., Scott, M.D., Irvine, A., 1999. Individual recognition in wild bottlenose dolphins: a field test using playback experiments. Animal behaviour 57, 41-50.

Scales, J.A., Wilkins, K.T., 2007. Seasonality and fidelity in roost use of the Mexican freetailed bat, Tadarida brasiliensis, in an urban setting. Western North American Naturalist 67, 402-408.

Searcy, W.A., Marler, P., Peters, S.S., 1981. Species song discrimination in adult female song and swamp sparrows. Animal Behaviour 29, 997-1003.

Slabbekoorn, H., Smith, T.B., 2002. Bird song, ecology and speciation. Philosophical Transactions of the Royal Society of London. Series B: Biological Sciences 357, 493-503.

Slater, P.J., 1989. Bird song learning: causes and consequences. Ethology Ecology \& Evolution 1, 19-46.

Slobodchikoff, C., Coast, R., 1980. Dialects in the alarm calls of prairie dogs. Behavioral Ecology and Sociobiology 7, 49-53. 
Soma, M., Garamszegi, L.Z., 2011. Rethinking birdsong evolution: meta-analysis of the relationship between song complexity and reproductive success. Behavioral Ecology, arq219.

Somers, P., 1973. Dialects in southern rocky mountain pikas, Ochotona princeps (Lagomorpha). Animal Behaviour 21, 124-137.

Stoddard, P., 1996. Vocal recognition of neighbors by territorial passerines. Ecology and evolution of acoustic communication in birds, 356-374.

Thomas, J.A., Stirling, I., 1983. Geographic variation in the underwater vocalizations of Weddell seals (Leptonychotes weddelli) from Palmer Peninsula and McMurdo Sound, Antarctica. Canadian Journal of Zoology 61, 2203-2212.

Whitehead, H., 1998. Cultural selection and genetic diversity in matrilineal whales. Science 282, 1708-1711.

Whiten, A., Goodall, J., McGrew, W.C., Nishida, T., Reynolds, V., Sugiyama, Y., Tutin, C.E., Wrangham, R.W., Boesch, C., 1999. Cultures in chimpanzees. Nature 399, 682-685.

Wiens, J.A., 1982. Song pattern variation in the sage sparrow (Amphispiza belli): dialects or epiphenomena? The Auk, 208-229.

Wiley, R.H., Richards, D.G., 1978. Physical constraints on acoustic communication in the atmosphere: implications for the evolution of animal vocalizations. Behavioral Ecology and Sociobiology 3, 69-94.

Wright, T.F., 1996. Regional dialects in the contact call of a parrot. Proceedings of the Royal Society of London. Series B: Biological Sciences 263, 867-872.

Wright, T.F., Wilkinson, G.S., 2001. Population genetic structure and vocal dialects in an amazon parrot. Proceedings of the Royal Society of London B: Biological Sciences 268, 609616.

Yovel, Y., Melcon, M.L., Franz, M.O., Denzinger, A., Schnitzler, H.-U., 2009. The voice of bats: how greater mouse-eared bats recognize individuals based on their echolocation calls. PLoS Comput Biol 5, e1000400. 
Table 1. Variance components. Restricted maximum likelihood variance component estimates for within bat, among bat, and among colony. Differences between shape categories are the biggest source of variation for most of the parameters measured. Males within each colony differed significantly in all six parameters, and there were regional differences in Max frequency and beginning frequency. Parameters marked with $* * *$ had a $p$-value of $<0.0001$, and those marked by $*$ had p-values of $<0.0083$.

\begin{tabular}{|l|l|l|l|l|l|l|}
\hline & \multicolumn{5}{|c|}{ Percent of total Variance } \\
\hline & $\begin{array}{l}\text { Among Shape } \\
\text { Groups }\end{array}$ & $\begin{array}{l}\text { Within } \\
\text { Bat }\end{array}$ & $\begin{array}{l}\text { Among } \\
\text { Bats in } \\
\text { Colony }\end{array}$ & $\begin{array}{l}\text { Among } \\
\text { Locations } \\
\text { in Region }\end{array}$ & $\begin{array}{l}\text { Among } \\
\text { Regions }\end{array}$ & Total \\
\hline Duration & 0 & 20 & $37^{* * *}$ & 11 & 32 & 100 \\
\hline Min Frequency & $66^{* * *}$ & 8 & $21^{* * *}$ & 0 & 5 & 100 \\
\hline Max Frequency & $75^{* * *}$ & 9 & $10^{* * *}$ & 0 & $6^{*}$ & 100 \\
\hline Beginning Frequency & $31^{* * *}$ & 22 & $21^{* * *}$ & 0 & $26^{*}$ & 100 \\
\hline Ending Frequency & $34 * * *$ & 15 & $34^{* * *}$ & 2 & 15 & 100 \\
\hline Peak Frequency & $39 * * *$ & 33 & $27^{* * *}$ & 1 & 0 & 100 \\
\hline
\end{tabular}


Table 2. Common song types. Forty-six distinct song types were found in the sample of 600 songs (100 per location). Song types were not equifrequent, the top three most common song types accounted for the vast majority of songs recorded, while the 30 least frequent types combined made up less than $10 \%$ of songs.

\begin{tabular}{|l|l|l|}
\hline Song Type & $\begin{array}{l}\text { Number } \\
\text { recorded }\end{array}$ & Frequency \\
\hline c-b & $\mathbf{1 6 9}$ & $\mathbf{2 8 . 2 \%}$ \\
\hline c & $\mathbf{1 2 8}$ & $\mathbf{2 1 . 3 \%}$ \\
\hline c-t-b & $\mathbf{9 2}$ & $\mathbf{1 5 . 3 \%}$ \\
\hline c-t & 30 & $5.1 \%$ \\
\hline c-b-c & 24 & $4.1 \%$ \\
\hline c-t-c & 24 & $4.1 \%$ \\
\hline c-b-c-b & 17 & $2.9 \%$ \\
\hline c-b-t-b & 14 & $2.4 \%$ \\
\hline c-b-t & 11 & $1.9 \%$ \\
\hline c-t-c-b & 9 & $1.5 \%$ \\
\hline c-t-c-t-b & 6 & $1.0 \%$ \\
\hline c-t-c-t-c & 5 & $0.9 \%$ \\
\hline t-c-t-b & 5 & $0.9 \%$ \\
\hline c-t-b-c & 4 & $0.7 \%$ \\
\hline c-t-b-c-t-b & 4 & $0.7 \%$ \\
\hline c-t-c-t & 4 & $0.7 \%$ \\
\hline
\end{tabular}

*There were 30 other song types that each accounted for $0.5 \%$ of songs recorded or less.

Table 3. Shape category frequency. Almost all the shape categories were found in at least half of the locations, and the three most common categories were seen at all locations.

\begin{tabular}{|c|c|c|c|}
\hline $\begin{array}{c}\text { Syllable } \\
\text { Shape }\end{array}$ & $\begin{array}{c}\text { Overall } \\
\text { Frequency }\end{array}$ & $\begin{array}{c}\text { Number of } \\
\text { Colonies } \\
\text { Found }\end{array}$ & $\begin{array}{c}\text { Colony } \\
\text { Frequency } \\
\text { Range }\end{array}$ \\
\hline $\mathrm{a}$ & 34 & 6 & $19-50$ \\
\hline $\mathrm{b}$ & 4 & 2 & $7-12$ \\
\hline $\mathrm{c}$ & 6 & 3 & $6-17$ \\
\hline $\mathrm{d}$ & 24 & 6 & $12-36$ \\
\hline $\mathrm{e}$ & 23 & 6 & $8-44$ \\
\hline $\mathrm{f}$ & 9 & 5 & $6-17$ \\
\hline
\end{tabular}




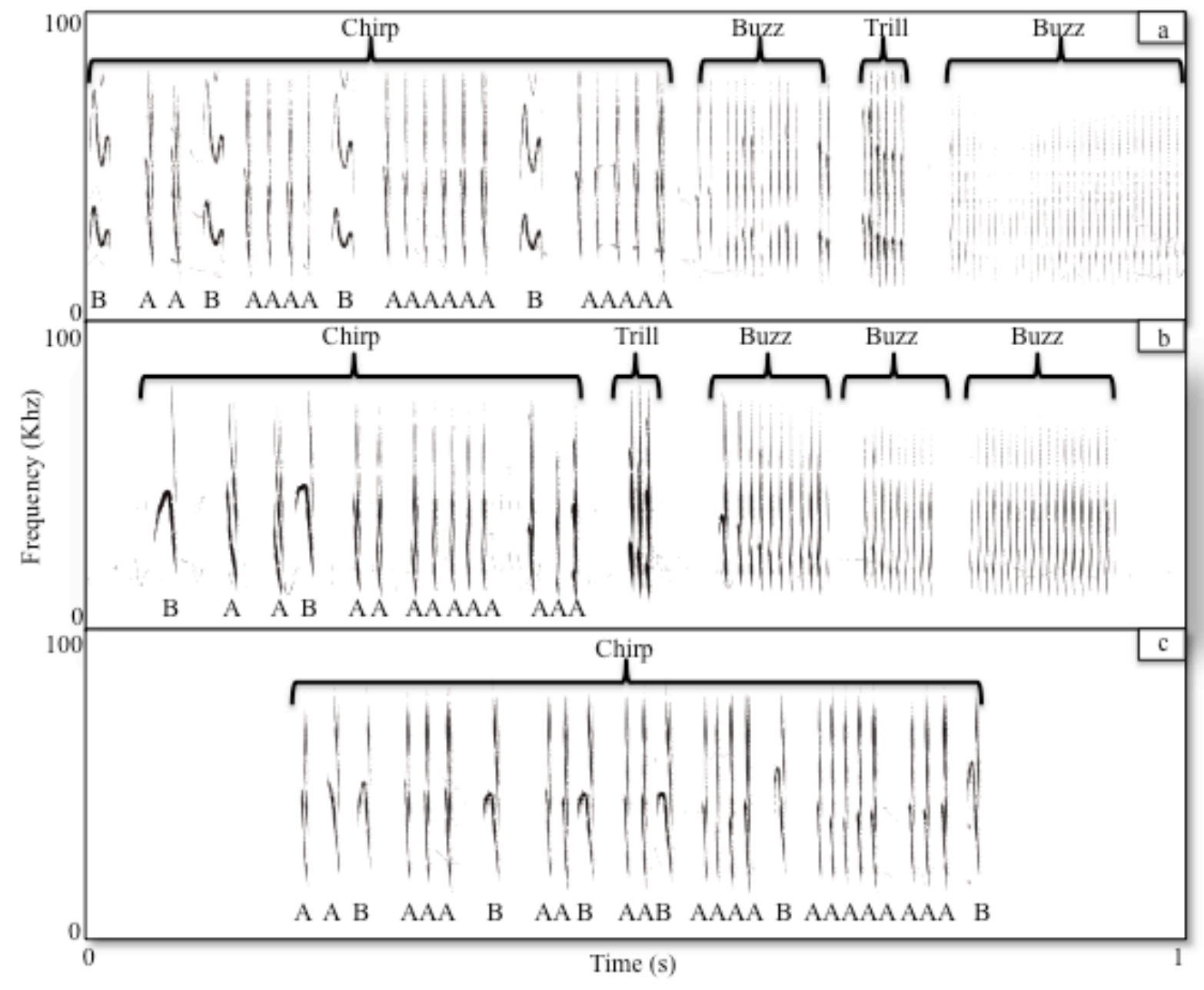

Figure 1. Brazilian free-tailed bat songs. Capital letters denote the two syllable types, and the brackets enclose the different phrases. Panel A shows a c-b-t-b song by a male from Jacksonville. Panels $\mathrm{b}$ and $\mathrm{c}$ are two different songs by a second male, note the change in type B syllable shape from that in panel (a) and the differences phrase order and syllable composition among the three songs. 


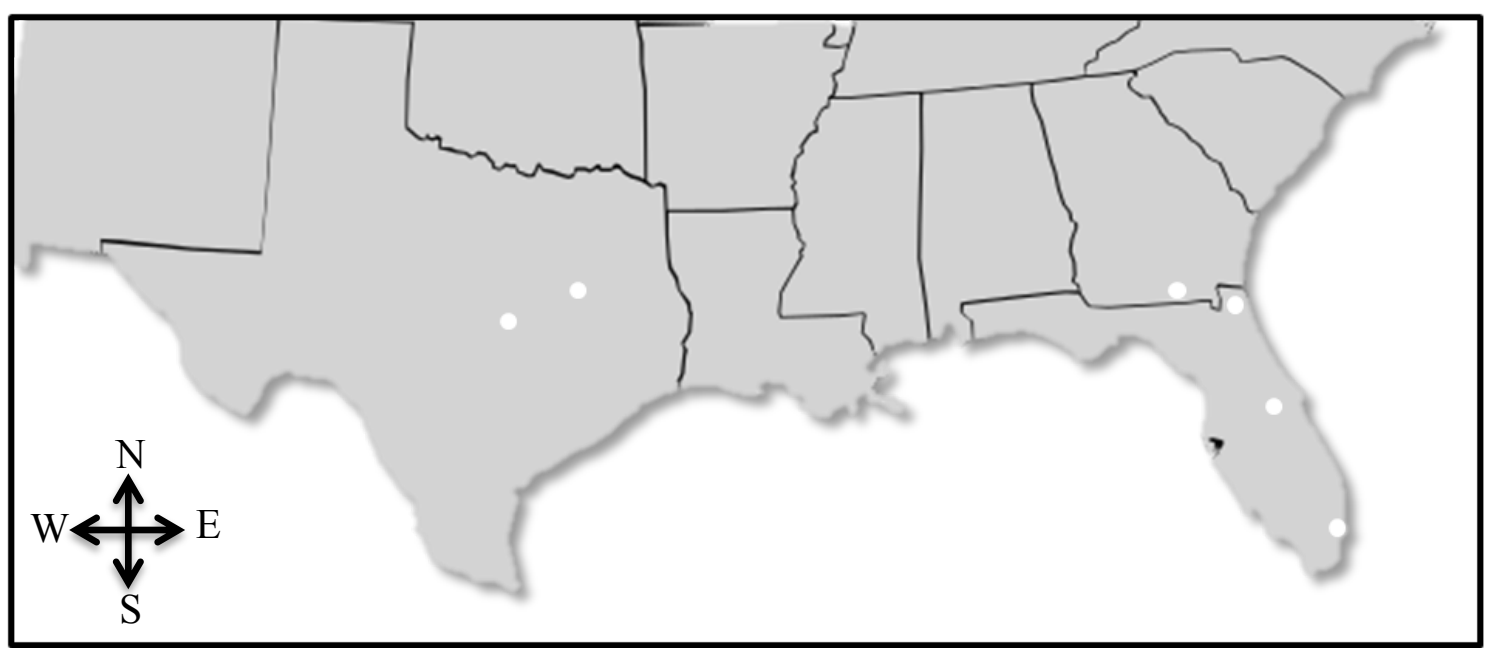

Figure 2. Map of study sites. The white circles represent the six study locations (from left to right Austin TX, College Station TX, Quitman GA, Jacksonville FL, Orlando FL and Miami FL.)
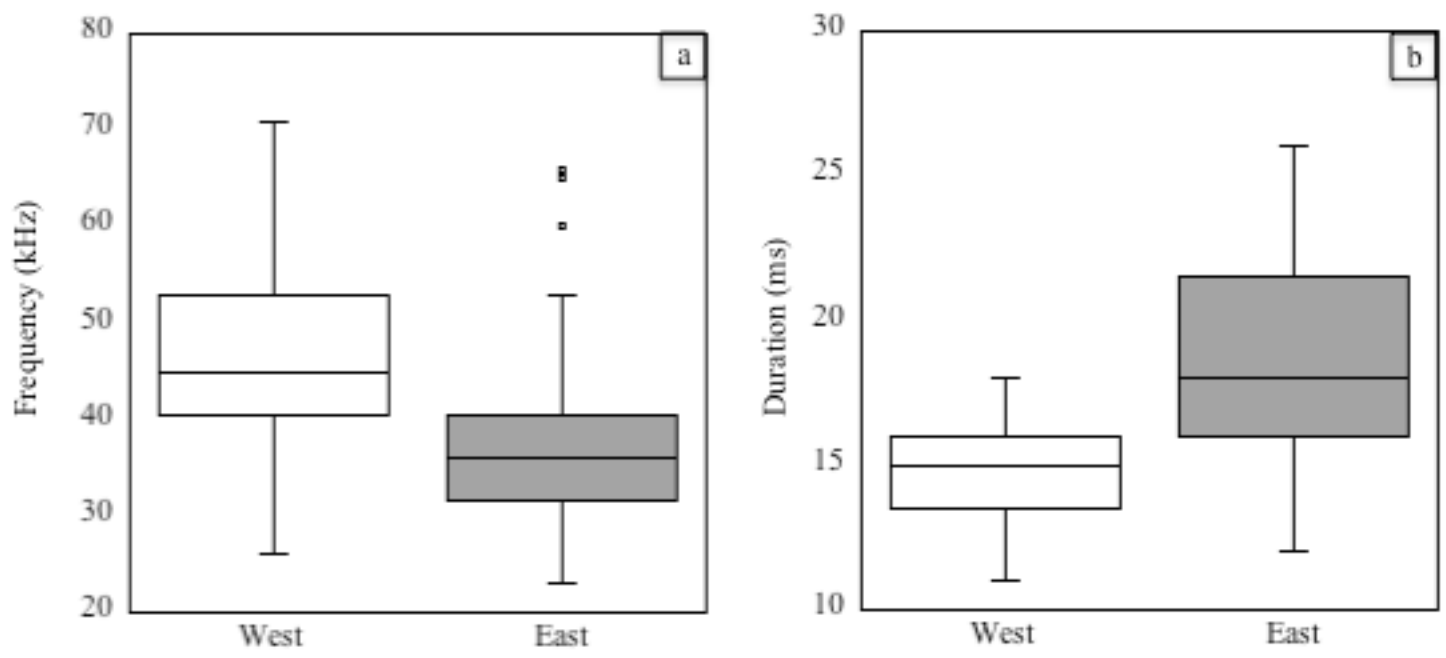

Figure 3. Regional differences in syllable parameters. Eastern bats produce type -B syllables which are (a) lower in frequency, and (b) longer in duration than those produced by their western counterparts. 


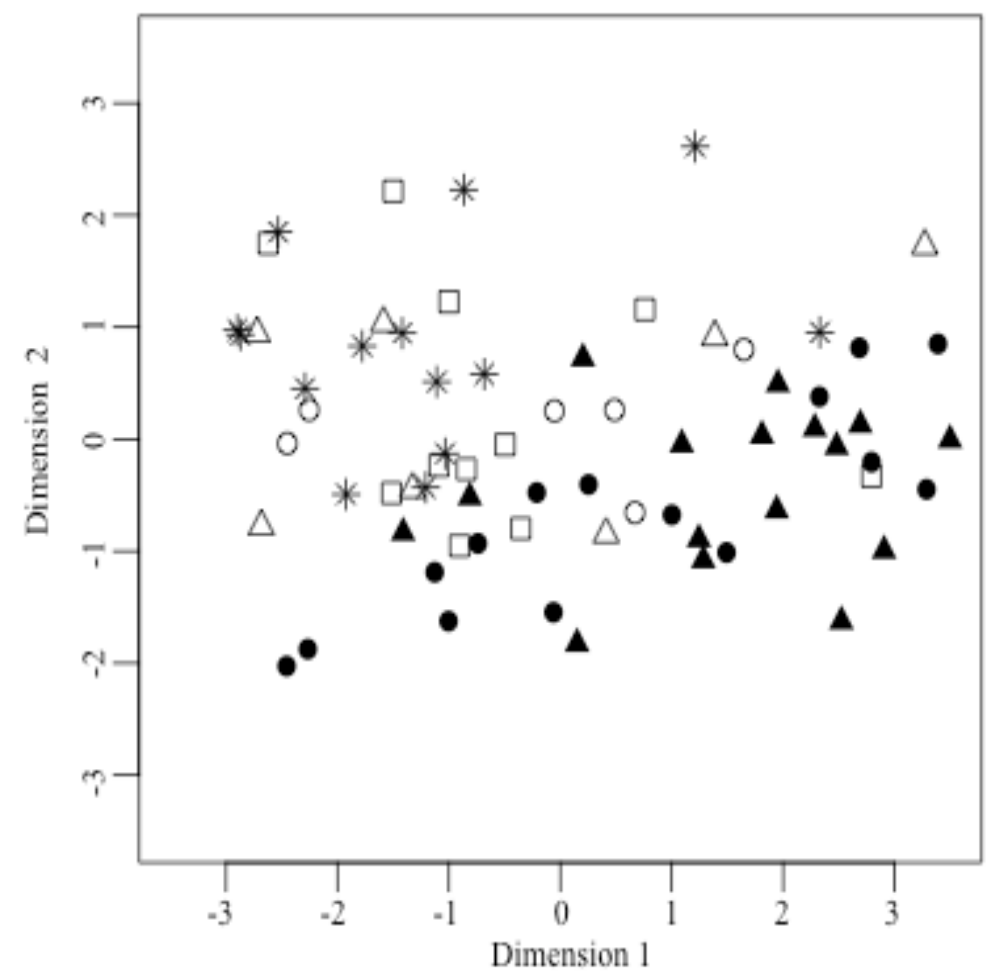

Figure 4. Multidimensional scaling analysis of song parameters. There is a distinct difference in syllable parameters between eastern (light symbols) and western bats (filled symbols). Each point represents one male, coded by location, $\square=$ Miami, $\bigcirc=$ Orlando, $\Delta=$ Jacksonville, $*=$ Quitman, $\boldsymbol{\Delta}=$ College Station,$\bullet=$ Austin. The proximity of the points indicates degree of similarity. 


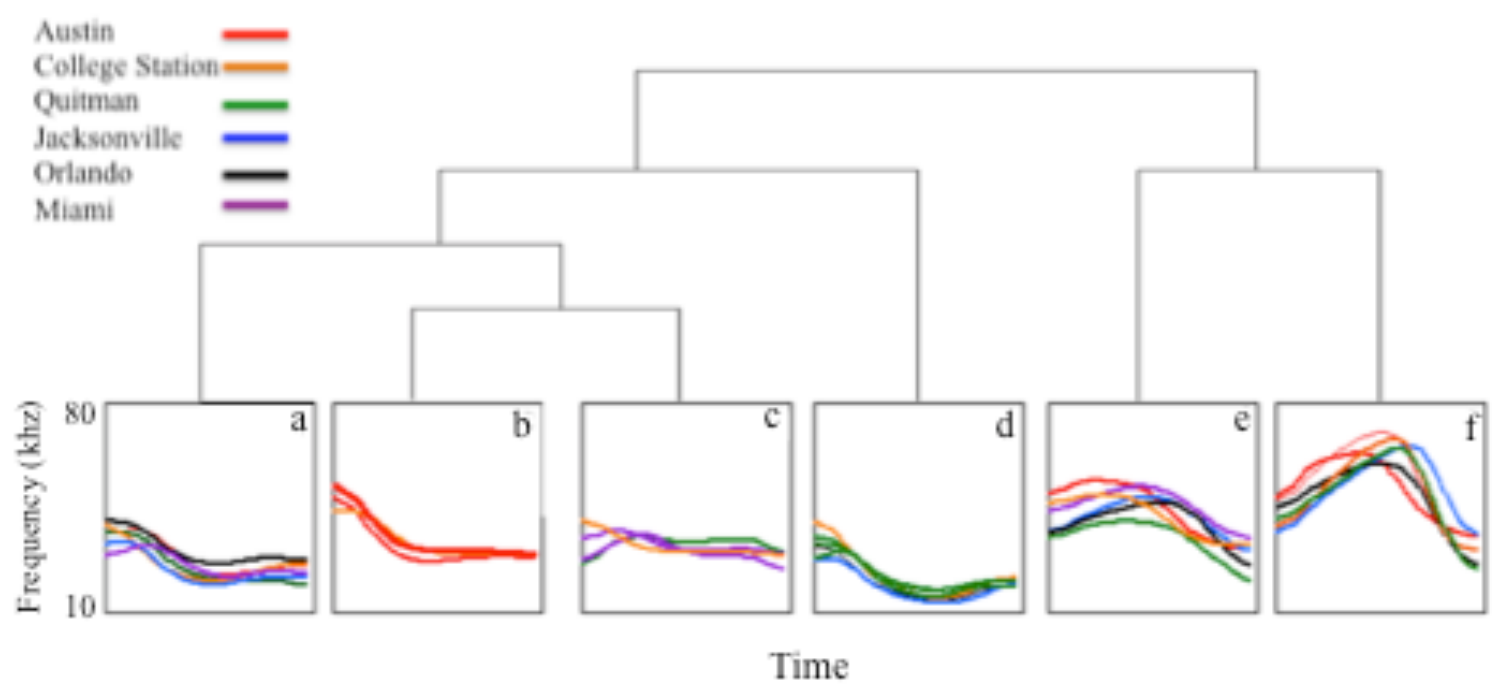

Figure 5. Type-B syllable shape categories. Type-B syllable shapes fall into one of six categories based on the their pattern of frequency modulations. The shapes are not colony distinctive, but rather most were found in at least half the locations studied.
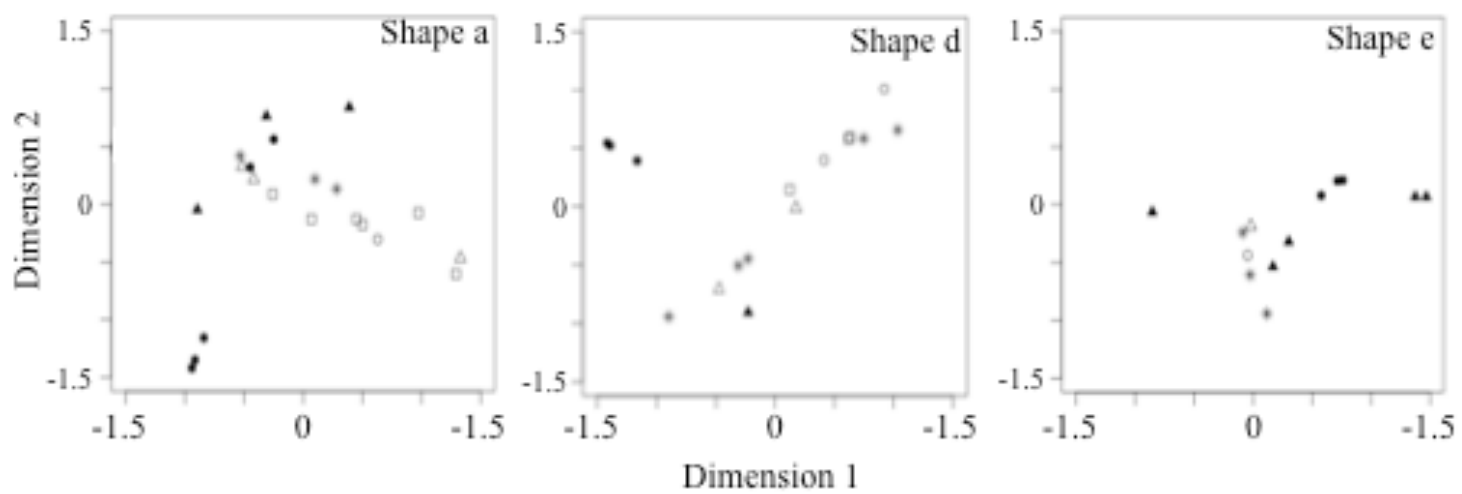

Figure 6. Multidimensional scaling analysis of common shape categories. There is considerable variation among bats in each of the shape categories. Bats within each category did not group according to their region of origin, indicating that the categories represent the same shape types at all locations. $\square=$ Miami, $\mathrm{o}=$ Orlando, $\Delta=$ Jacksonville, $*=$ Quitman, $\boldsymbol{\Delta}=$ College Station,$\bullet=$ Austin. The proximity of the points indicates degree of similarity. 


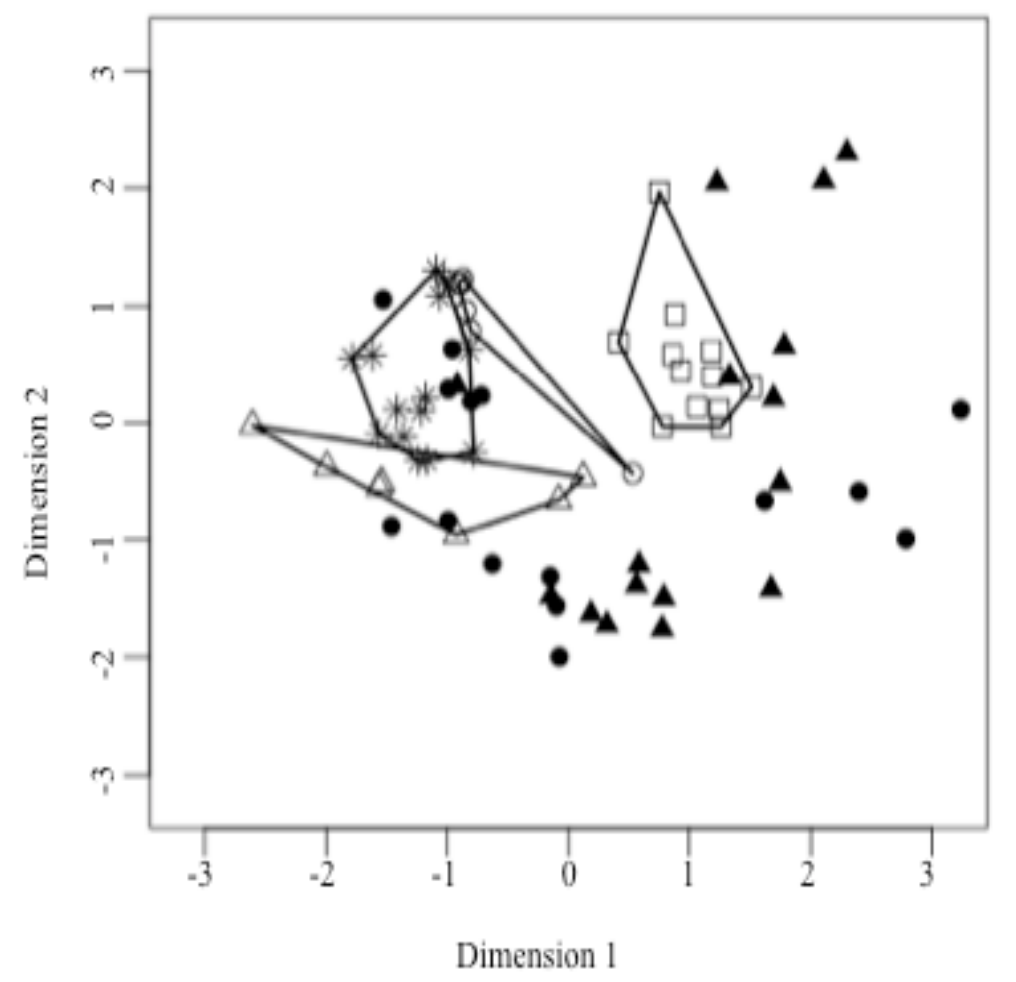

Figure 7. Multidimensional scaling analysis of spectral contours. Males from the eastern colonies tend to form distinct groups while there is considerable overlap between the two western colonies. Each point represents the average type B syllable contour of one male, coded by location $\square=$ Miami, $\circ=$ Orlando, $\Delta=$ Jacksonville, $*=$ Quitman, $\boldsymbol{\Delta}=$ College Station , $\bullet=$ Austin. The proximity of the points indicates degree of similarity, minimum area polygons enclose the males from each of the eastern colonies. 

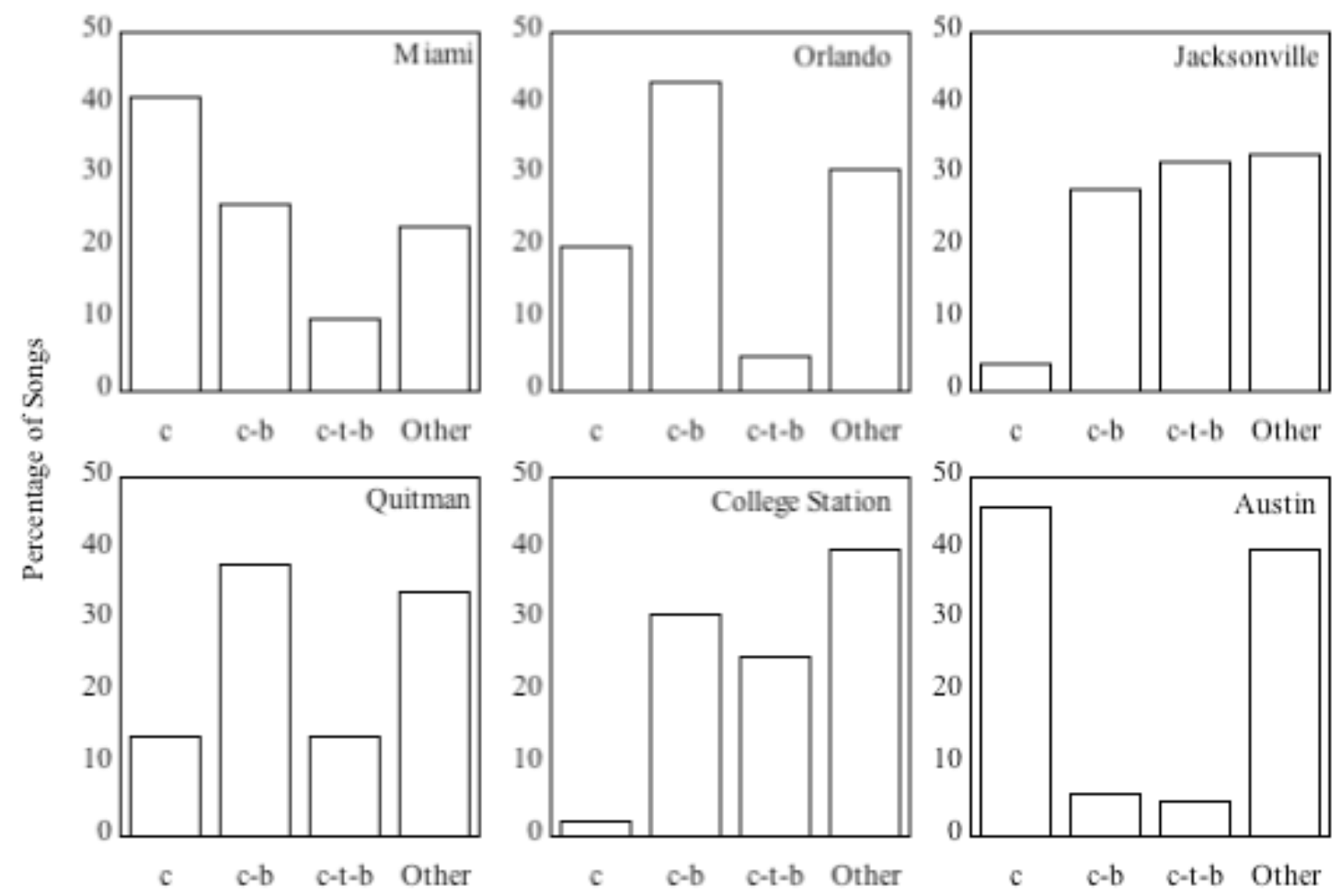

Song Type

Figure 8. Common song type usage patterns. Colonies differed significantly in how much they used each of the three most common song types, creating unique patterns of song type usage for each location. In all cases the last bar to the right represents the aggregate of all other less common song types. 


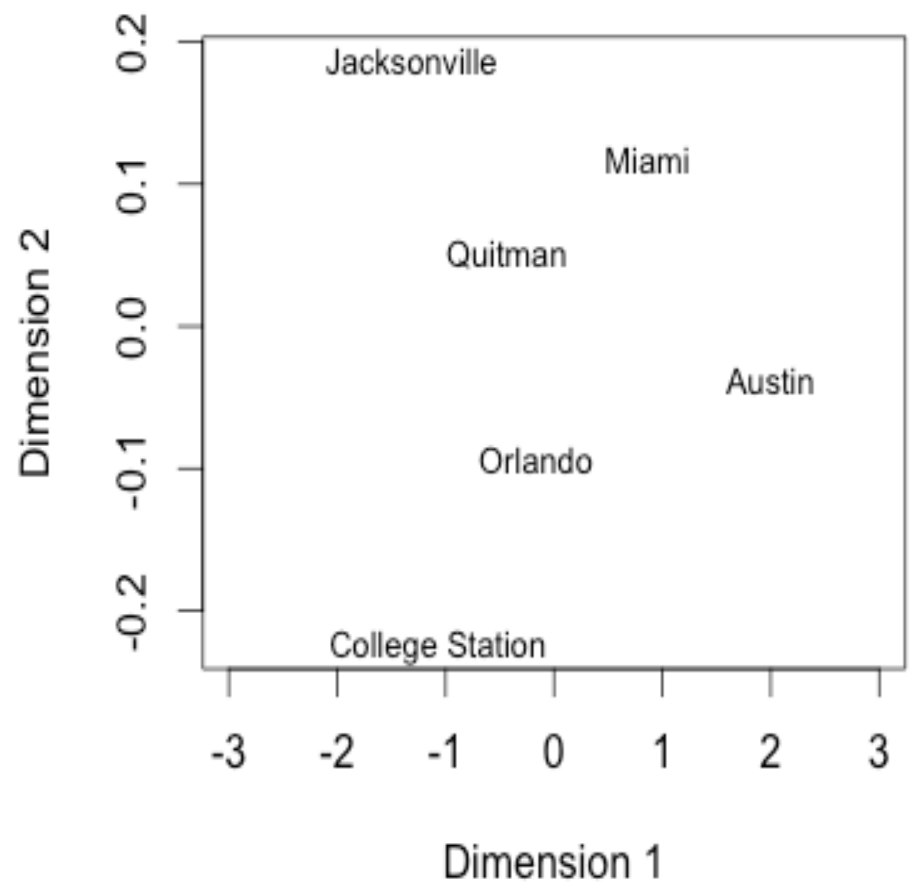

Figure 9. Multidimensional scaling analysis of song type usage. Colonies do not aggregate based on song usage similarity as would be expected by geographic proximity, each site is its own syntactical dialect.

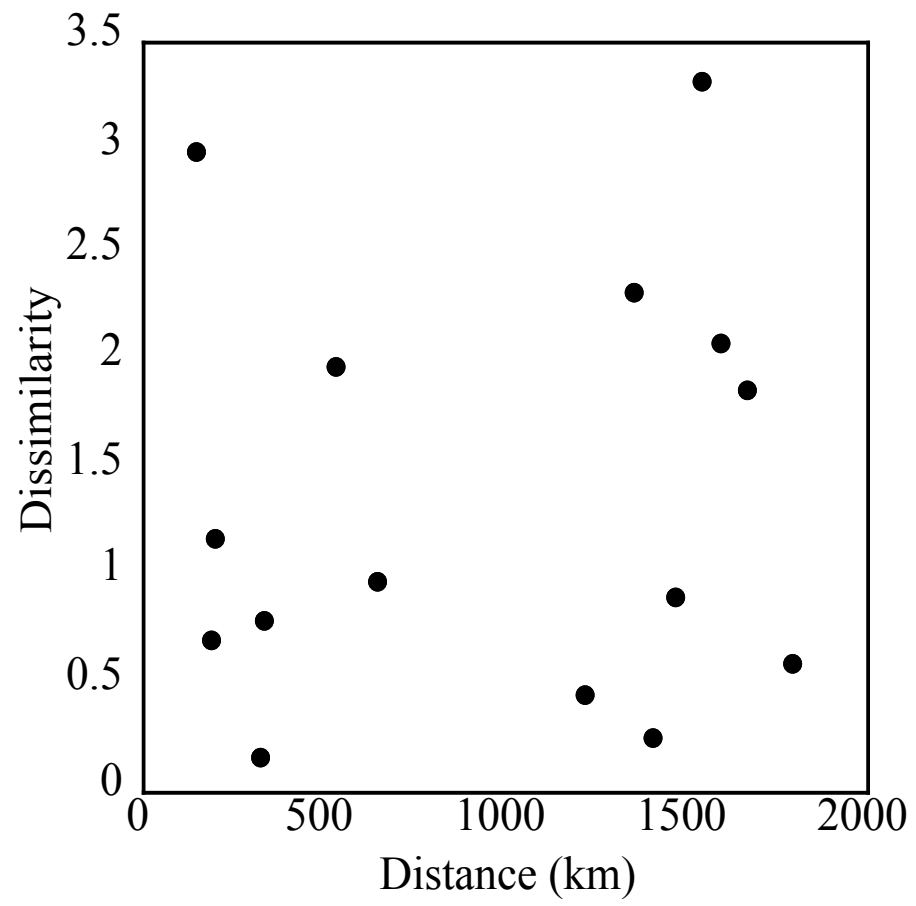


Figure 10. Distance vs. song type dissimilarity. There is no correlation between syntactical similarity and geographical distance. Some of the colonies that were furthest away ended up being more similar to each other than colonies which were the closest. Each point represents a pair of colonies.
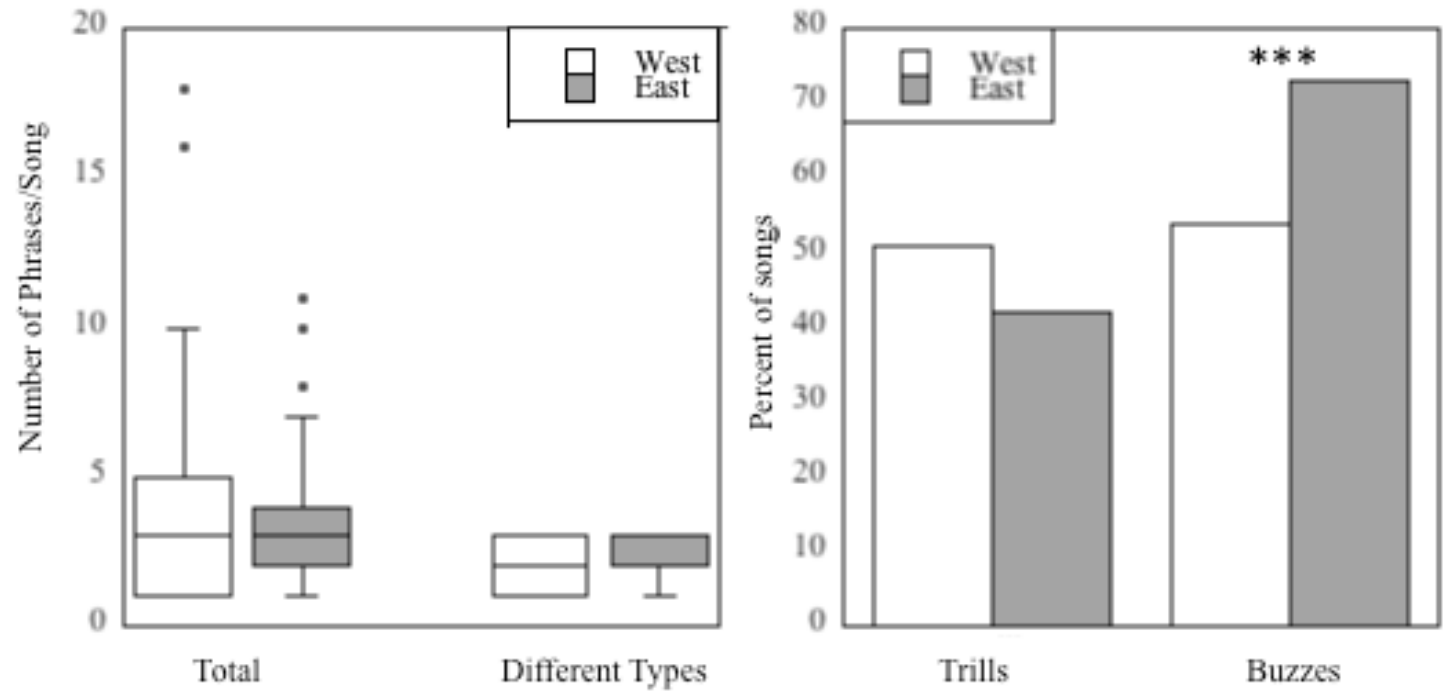

Figure 11. Song composition of migratory and sedentary colonies. There was no difference in song complexity nor percentage of songs with trills between migratory and sedentary populations. However sedentary populations did have a higher proportion of songs with buzzes. 